\title{
Active Choices
}

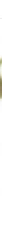

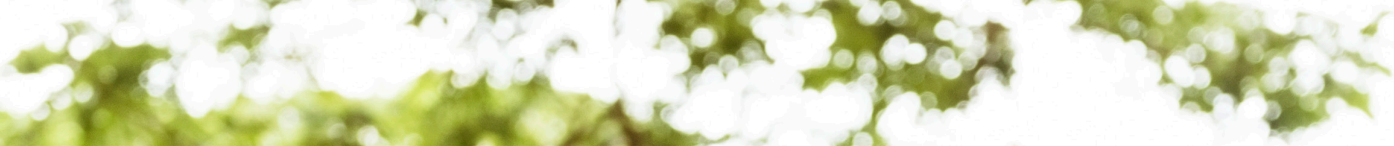
7.

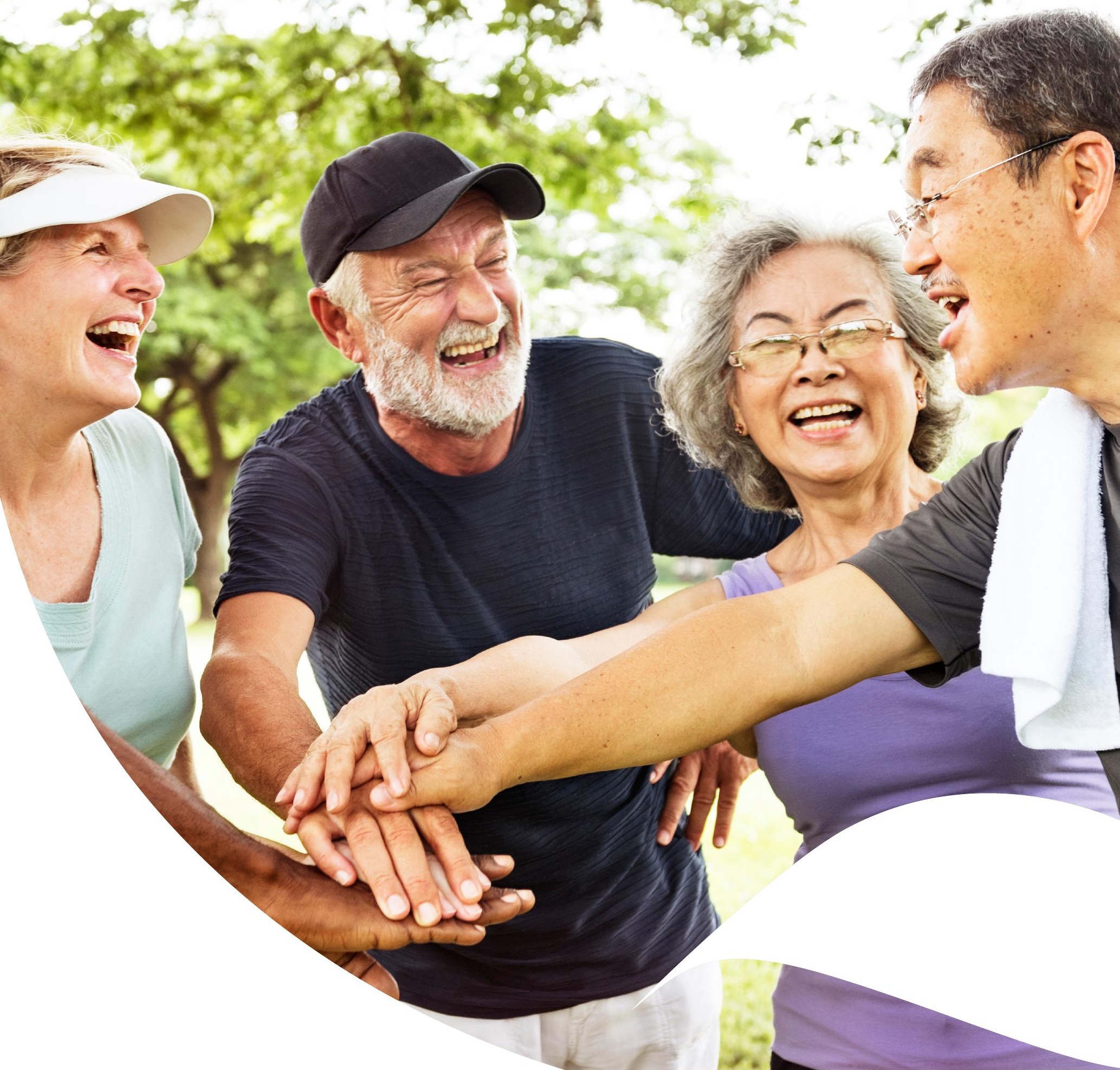




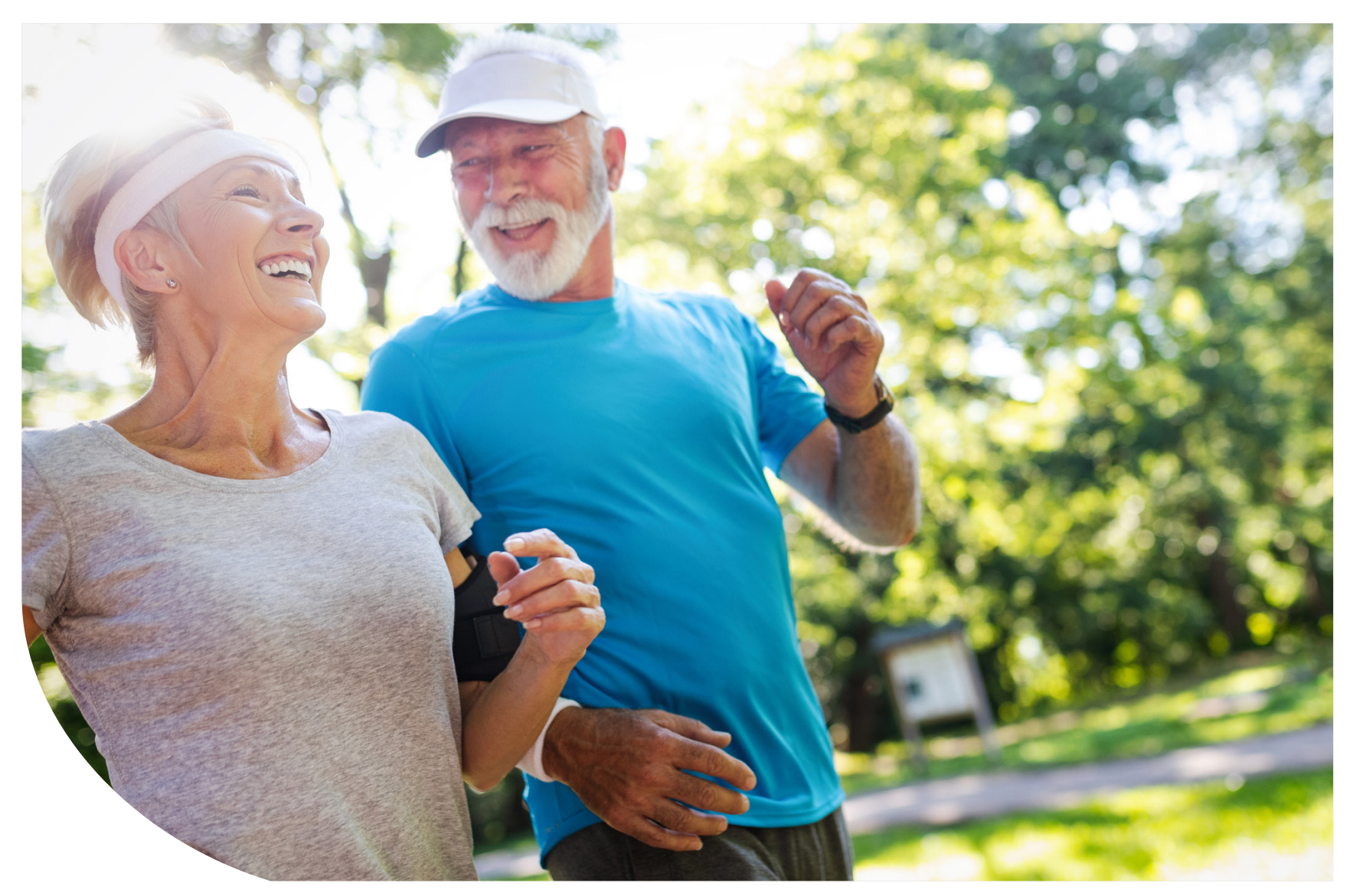

\section{About Active Choices}

Active Choices is a 12-week program that helps you be more physically active and socially connected within your local community.

The program aims to link you to fun, social, local group activities of your choosing, and provide you with support strategies to self-manage your physical activity during and after the program ends.

\section{About this booklet}

This resource booklet will support you during the Active Choices program. It contains educational materials and helpful tips to become and remain physically active. It also contains materials and tools for choosing and managing the physical activities you want to try.

Particular sections of the booklet we'll discuss at our initial consultation, when we check-in with you by telephone in weeks 4 and 8, and when you return for your final consultation meeting in week 12. Other sections of the booklet, like the physical activity log, will be completed by you independently at home.

Regular reference to the information and materials in this booklet throughout the program will support you in achieving your physical activity goals.

If you have any questions about the contents of this booklet or the Active Choices program, be sure to ask us.

\section{Program Structure}

Week 0: Start measures of your physical activity and health

\section{$\checkmark$}

Week 1 to 12: Active Choices Program

\section{$\checkmark$}

Week 1: Initial Consultation - Getting Started

- Develop your personal Active Choices program for weeks 1 to 4

\section{$\checkmark$}

Week 4: Telephone Check-In

- Review your progress during weeks 1 to 4

- Develop your personal Active Choices program for weeks 5 to 8

\section{$\checkmark$}

Week 8: Telephone Check-In

- Review your progress during weeks 5 to 8

- Develop your personal Active Choices program for weeks 9 to 12

\section{$\checkmark$}

Week 12: Final Consultation - Moving Forward

- Review your progress during weeks 9 to 12

- Develop your plan for self-managing physical activity into the future

\section{$\downarrow$}

Week 13 to 24: Self-Manage Physical Activity

\section{$\downarrow$}

Week 24: Final measures of your physical activity and health 


\section{Contents}

Choices

\begin{tabular}{|l|l|}
\hline About Active Choices & 1 \\
\hline Program Structure & 2 \\
\hline Contents Page & 3 \\
\hline Making sure your activities are safe & 5 \\
\hline Why is physical activity important? & 6 \\
\hline How physically active are you? & 7 \\
\hline What are the different types of physical activity? & 8 \\
\hline What types of physical activity would you like to do? & 9 \\
\hline Your local opportunities for physical activity & 10 \\
\hline Your physical activity goals | Week 1 to 4 & 11 \\
\hline Your physical activity plan | Week 1 to 4 & 12 \\
\hline Tips for staying physically active & 13 \\
\hline Physical activity logbook | Week 1 to 4 & 15 \\
\hline Week 4 Telephone Check-In & 27 \\
\hline Physical activity logbook | Week 5 to 8 & 17 \\
\hline Week 8 Telephone Check-In & 21 \\
\hline Physical activity logbook | Week 9 to 12 & 23 \\
\hline Week 12 Consultation & 29 \\
\hline
\end{tabular}




\section{Physical activity logbook | Week 1 to 4}

During the course of the Active Choices program, we would like you to keep a record of the physical activity you do each day. Through self-monitoring your physical activity, you will be able to keep track of your progress and assess whether you are meeting your goals.

Using the logbook provided, please record the following details about the physical activity

you complete during weeks 1 to 4 of the program:

The type of activity you did (e.g., Pilates class) - write the name of the activity in the

'activity' column.

- The amount of time you did the activity for (e.g., 60 minutes) - write the number of

minutes in the 'day of the week' box.

An example of how to fill in the logbook is provided below.

\section{Activity}

Walking group

Pilates class

\section{Week 1}

Sun Mon Tue Wed Thur Fri Sat

60

60

\section{Week 4: Telephone Check-In}

We will check in with you in four weeks time to see how you are going with your Active Choices program. Using your self-monitoring log, we will work with you to review your goal progress. We'll also see if you'd like to change or continue with your Active Choices and help you set your goals for weeks 5 to 8

Let's now agree on a time for your Week 4 Telephone Check-In:

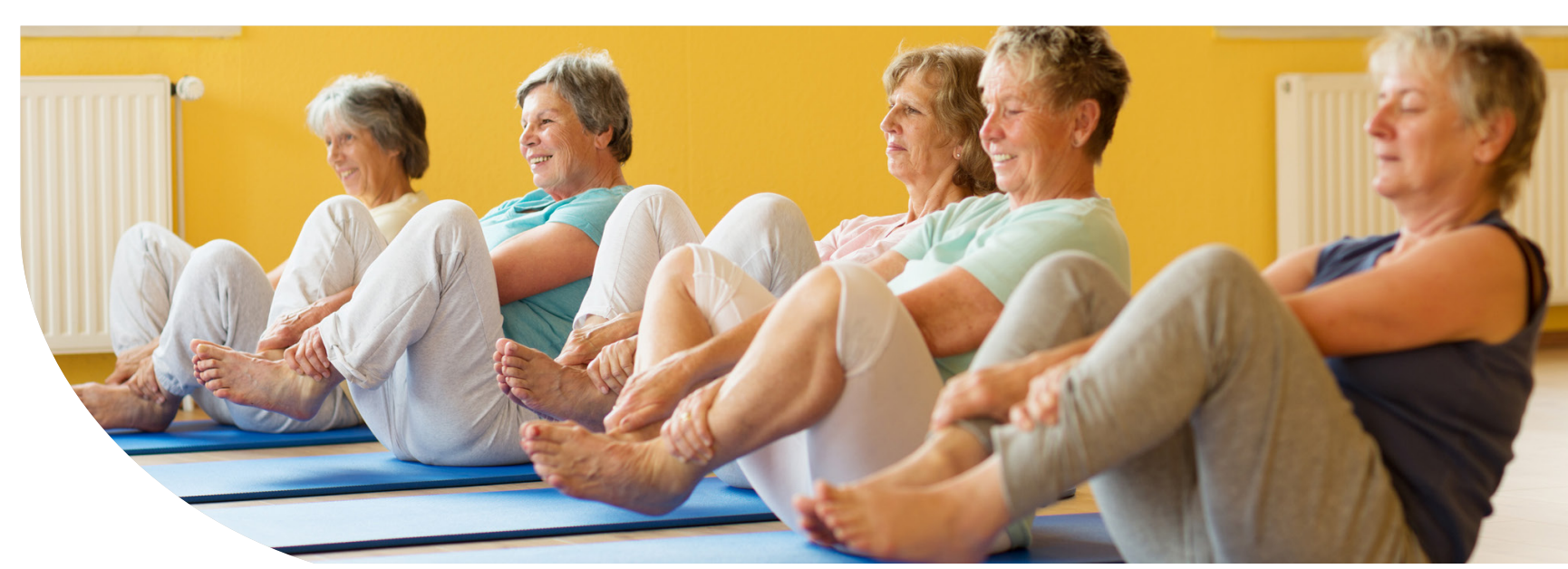

\begin{tabular}{|c|c|c|c|c|c|c|c|c|c|c|c|c|c|c|c|c|c|c|c|c|}
\hline \multicolumn{7}{|c|}{ Week 2} & \multicolumn{7}{|c|}{ Week 3} & \multicolumn{7}{|c|}{ Week 4} \\
\hline Sun & Mon & Tue & Wed & Thur & Fri & Sat & Sun & Mon & Tue & Wed & Thur & Fri & Sat & Sun & Mon & Tue & Wed & Thur & Fri & Sat \\
\hline 60 & & & & & & & 60 & & & & & & & 60 & & & & & & \\
\hline & 60 & & & & & & & 60 & & & & & & 60 & & & & & & \\
\hline
\end{tabular}

60
60 